\title{
Quantitative Evaluation of the Direct Uptake of Organic Nitrogen by Tomato Roots Associated with Plant Growth and Water Uptake: Use of a Root Chamber with HPFM
}

\author{
Daisuke Yasutake ${ }^{1}$, Aksoy Kemal Osman ${ }^{1}$, Kazuki KanO ${ }^{2}$, Sheheli Islam ${ }^{1}$, Midori Hikashi', \\ Yuki $\mathrm{SAGO}^{3}$, Katsumi IshIKAWA ${ }^{1}$ and Masaharu KITANO ${ }^{4}$ \\ ${ }^{1}$ Faculty of Agriculture, Kochi University, B200 Monobe, Nankoku, Kochi 783-8502, Japan \\ ${ }^{2}$ Graduate School of Agriculture, Biological Production Science, Ibaraki University, \\ 3-21-1 Chuuo, Ami, Inasaki, Ibaraki 300-0393, Japan \\ ${ }^{3}$ Department of Environmental and Life Sciences, Toyohashi University of Technology, \\ 1-1 Hibarigaoka, Tempaku-cho, Toyohashi, Aichi 441-8580, Japan \\ ${ }^{4}$ Faculty of Agriculture, Kyushu University, 6-10-1 Hakozaki, Higashi-ku, Fukuoka 812-8581, Japan
}

(Received March 24, 2012; Accepted May 25, 2012)

\begin{abstract}
Characteristics of direct uptake of organic nitrogen by tomato roots associated with plant growth and water uptake were analyzed quantitatively using a root chamber equipped with a highpressure flowmeter. The rate of root nutrient uptake was evaluated using the nutrient concentration in the xylem sap collected from the stem stump and the water uptake rate measured by the flowmeter. There was a difference in nutrient content in the xylem sap of the roots grown with or without organic nitrogen (amino acids), suggesting the direct uptake of them. The rate of organic nitrogen uptake was different depending on the type of organic nitrogen used, and was increased with plant growth through water uptake. Furthermore, the increase in water uptake supposed to be daytime transpiration induced a higher rate of organic nitrogen uptake, whereas the rate of nitrate nitrogen uptake either remained the same or increased slightly. As a result, the ratio of organic nitrogen uptake to total nitrogen uptake increased from approximately $15 \%$ to $40 \%$ with the water uptake increase.
\end{abstract}

Keywords : amino acid, direct uptake, root chamber, tomato, xylem sap

\section{INTRODUCTION}

Nitrogen $(\mathrm{N})$ is one of the most important nutrient elements for plant growth; therefore, $\mathrm{N}$ acquisition/utilization by plants has been studied extensively (Taiz and Zeiger, 2006). In particular, from the point of view of plant mineral nutrition, many researches have tried to understand the characteristics of uptake of nitrate nitrogen $\left(\mathrm{NO}_{3}^{-}\right)$and ammonium nitrogen $\left(\mathrm{NH}_{4}^{+}\right)$by roots.

On the other hand, a hot topic that plant roots may be able to absorb organic $\mathrm{N}$ directly as well as mineral (inorganic) $\mathrm{N}$, has recently become the focus of attention (e.g. Jones et al., 2005). This hypothesis seemed to be suggested from an imbalance between $\mathrm{N}$ mineralization in the root zone and $\mathrm{N}$ content in the plant body, and/or experiments on plant growth where amino acids were used as the source of N (Spoerl, 1948; Ghosh and Burris, 1950). Recently, Näsholm et al. (2001) and

Corresponding author: Daisuke Yasutake, fax: +81-88-864-5127, e-mail : yasutake@kochi-u.ac.jp 


\section{YASUTAKE ET AL.}

Ge et al. (2009) showed root direct uptake in some agricultural crops (tomato and wheat) by tracer experiments using dual-labeled $\left({ }^{13} \mathrm{C}\right.$ and $\left.{ }^{15} \mathrm{~N}\right)$ glycine. Furthermore, Nihei et al. (2008), using realtime autoradiographic imaging, observed that rice roots successively take up the amino acid alanine. Thus, evidence supporting the direct uptake of organic $\mathrm{N}$ by roots has already been shown; however, most of the data are qualitative in nature, and a thorough quantitative study has yet to be performed.

For quantitative evaluation of characteristics of nutrient uptake by roots, Yasutake et al. (2011) developed a root chamber, which is used with a high-pressure flowmeter (HPFM) for analyzing hydraulic characteristics of the plant body (Nagasuga et al., 2000; Nagasuga and Kubota, 2012).

In our study, the root chamber equipped with a HPFM was used to quantitatively evaluate the direct uptake of organic $\mathrm{N}$ in the simple form (i.e. amino acid) by tomato roots. We focused on the fundamental properties of direct uptake, that is, responses to (1) plant growth and (2) root water uptake, because the former could be associated with root volume and plant nutrient demand (Taiz and Zeiger, 2006); and the latter with nutrient uptake (Sago et al., 2011). This paper describes the results from two experiments examining the responses to plant growth (Experiment I) and root water uptake (Experiment II).

\section{MATERIALS AND METHODS}

\section{Root chamber with a HPFM for quantitative evaluation of root nutrient uptake}

Figure 1 shows a schematic diagram of the root chamber with the HPFM used for evaluation of root uptake function, which was explained in detail by Yasutake et al. (2011). A root system is installed into the root chamber (diameter of $19 \mathrm{~cm}$ and height of $30 \mathrm{~cm}$ ) filled with arbitrary nutrient solution, and the pressurized water produced by the HPFM (Nagasuga et al., 2000) then flows into the chamber where the water and dissolved nutrients are transported into the root. The HPFM regulates the pressure over a wide range and measures the pressure and water flow rate.

Under steady-state condition, the water flow rate $(F)$ in the HPFM is the same as the rate of water uptake by roots $\left(J_{\mathrm{w}}\right)$ in the chamber:

$$
J_{\mathrm{w}}=F
$$

Furthermore, by analyzing the concentration $\left([\mathrm{M}]_{\mathrm{xy}}\right)$ of nutrient $\mathrm{M}$ in the xylem sap exuding from the root stump, the rate of nutrient $\mathrm{M}$ uptake by root $\left(J_{\mathrm{M}}\right)$ can be evaluated using the following equation:

$$
J_{\mathrm{M}}=J_{\mathrm{w}}[\mathrm{M}]_{\mathrm{xy}}
$$

The root chamber was set in a water bath $(40 \times 55 \times 30 \mathrm{~cm})$ with a heater $(300 \mathrm{~W}$ Black Heater, Gex Co., Ltd., Osaka, Japan) and a cooler (LPA2, Orion Machinery Co., Ltd., Nagano, Japan) with a temperature controller (NES-1100J, Nisiden Sangyo Co., Ltd., Tokyo, Japan).

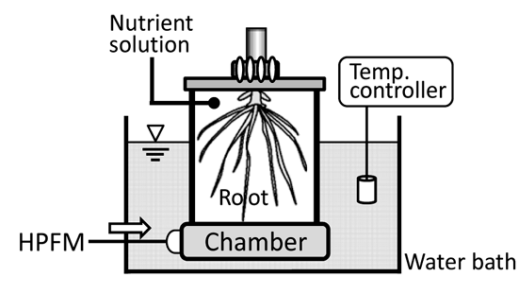

Fig. 1 Schematic diagram of a root chamber installed in a water bath with a temperature controller. The root chamber is connected to a high-pressure flowmeter (HPFM). 


\section{DIRECT UPTAKE OF ORGANIC NITROGEN BY ROOTS}

\section{Experiment I: Response to plant growth}

Four weeks after sowing, the tomato plants (Lycopersicon esculentum Mill. cv. Hausu momotaro) were transplanted to an NFT hydroponic system and grown with a nutrient solution prepared on the basis of the A-prescription of Otsuka House (Otsuka Chemical Co., Ltd., Osaka, Japan) at an electrical conductivity (EC) of $1.5 \mathrm{dS} \mathrm{m}^{-1}$ in a greenhouse at the Faculty of Agriculture, Kochi University. The plants in Exp. I were grown in the NFT system for 1, 2, or 3 months. The plants were cut at the stem base, and the roots were rinsed with tap water before setting them in the root chamber filled with the nutrient solution at an $\mathrm{EC}$ of $0.52 \mathrm{dS} \mathrm{m}^{-1}\left(\mathrm{NO}_{3}^{-}\right.$concentration $2 \mathrm{mmol} \mathrm{L}^{-1}$ ) and constant temperature of $25^{\circ} \mathrm{C}$, in which 3 different types of amino acid (glycine (Gly), alanine (Ala), and methionine (Met)) were then added at a concentration of 2 mmol $\mathrm{L}^{-1}$ (Org-N treatment). The reason for using these amino acids in this study was that they might be absorbed by roots with different patterns because Nihei et al. (2009) observed the difference in plant growth according to them as nitrogen source. The control plants received a nutrient solution without amino acids (Control treatment). Pressure ( $0.15 \mathrm{MPa})$ was applied to the chamber, and after reaching a steady-state, the xylem sap exuding from the stem stump was sampled.

The sap samples were filtered through a $0.45 \mu \mathrm{m}$ filter (Millex, Merck, Germany) and were derivatized with an AccQ-Fluor Reagent Kit (Waters Corporation, USA). The concentrations of Gly, Ala, and Met $\left.\left([\mathrm{Gly}]_{\mathrm{xy}},[\mathrm{Ala}]_{\mathrm{xy}} \text {, and [Met }\right]_{\mathrm{xy}}\right)$ were then analyzed using a high-performance liquid chromatograph (HPLC; Waters Corporation), which comprised a pump (600 E), a fluorescence detector (2475), a column oven (N62009), a column (AccQ-Tag, $3.9 \times 150 \mathrm{~mm}$ ), and an autosampler (717 plus), under the following conditions: phase A, 10\% AccQ-Tag Eluent concentrate A (Waters Corporation); phase $\mathrm{B}, 100 \%$ acetonitrile; phase $\mathrm{C}, \mathrm{H}_{2} \mathrm{O}$; flow rate, $1 \mathrm{~mL} \mathrm{~min}^{-1}$; injection volume, $10 \mu \mathrm{L}$; column temperature, $37^{\circ} \mathrm{C}$.

Using the values of $J_{\mathrm{w}}$ measured by the HPFM and of [Gly $]_{\mathrm{xy}}$, [Ala $]_{\mathrm{Xy}}$, and [Met $]_{\mathrm{Xy}}$ determined by the HPLC, we evaluated $J_{\mathrm{M}}\left(J_{\mathrm{Gly}}, J_{\mathrm{Ala}}\right.$, and $J_{\text {Met, }}$ see Eq.(2)) at different growth stages; namely, 1 , 2 , and 3 months after transplanting.

\section{Experiment II: Response to water uptake}

Four weeks after sowing, the tomato plants were transplanted to hydroponic pots $(3 \mathrm{~L}$ in volume) filled with the nutrient solution and were grown in the greenhouse an additional 4 weeks. Three plants were used for Exp. II and the procedure of setting the roots into the chamber was the same as in Exp. I. The root chamber was filled with the nutrient solution, at an EC of $0.52 \mathrm{dS}$ $\mathrm{m}^{-1}$, supplemented with Gly and Ala at a concentration of $2 \mathrm{mmol} \mathrm{L}^{-1}$ (Org-N treatment) or with no amino acid (Control treatment). Four different pressures of $0.025,0.05,0.1$, and $0.15 \mathrm{MPa}$ were applied to the chamber so as to change the $J_{\mathrm{w}}$ to a range similar to the usual root uptake rate (i.e. $0-25 \mu \mathrm{L} \mathrm{s}^{-1} /$ plant). After reaching the steady-state condition, $J_{\mathrm{w}}$ was measured and the xylem sap exuding from the stem stump was sampled. [Gly $]_{\mathrm{xy}}$ and $[\mathrm{Ala}]_{\mathrm{xy}}$ in the sap were determined using the HPLC as described in Exp. I. The $\mathrm{NO}_{3}^{-}$concentration in the sap $\left(\left[\mathrm{NO}_{3}^{-}\right]_{\mathrm{xy}}\right)$ was also measured using a reflectometer (RQflex plus 10, Merck, Germany). $J_{\mathrm{Gl}}, J_{\mathrm{Ala}}$, and $J_{\mathrm{NO},}$ at the different rates of root water uptake were evaluated from Eq. (2) using $J_{\mathrm{w}},[\mathrm{Gly}]_{\mathrm{xy}},[\mathrm{Ala}]_{\mathrm{xy}}$, and $\left[\mathrm{NO}_{3}^{-}\right]_{\mathrm{xy}}$.

\section{RESULTS AND DISCUSSION}

Nutrient content in the root xylem sap is a reflection of the characteristics of root nutrient uptake (Taiz and Zeiger, 2006). Figure 2 shows examples of the HPLC images of the xylem sap in the Org-N and Control treatments. For the Org-N treatment, Gly and Ala were detected in the peaks appearing at 21.4 and $26.2 \mathrm{~min}$, respectively, while their peak heights were almost zero or extremely lower in the Control treatment. This is consistent with the study by Matsumoto et al. (2000), which analyzed the HPLC chromatograms of the xylem sap collected from chingensai grown in soil with organic fertilizer and in inorganic hydroponics. These facts indicate that the 


\section{YASUTAKE ET AL.}

peaks for Gly and Ala in the Org-N treatment resulted from direct uptake of them by the root surface, and not by $\mathrm{N}$ assimilation within the root (Taiz and Zeiger, 2006). Direct uptake should be driven by transport mechanisms present on the root cell membrane. Two specific amino acid transporters, LHT1 and AAP1, were recently identified on root surface in the model plant Arabidopsis thaliana L. (Hirner et al., 2006; Lee et al., 2007; Svennerstam et al., 2007). Therefore, the root chamber with HPFM seems to be applicable for quantitative evaluation and analysis of direct uptake of organic $\mathrm{N}$ by roots.

Figure 3 shows the relationship between $J_{\mathrm{w}}$ and root dry weight for the Org-N and Control treatments in Exp. I. The dry weight for the growing period (1, 2, and 3 months) was $2.51 \pm 1.04$, $13.47 \pm 0.98$, and $28.37 \pm 5.01 \mathrm{~g} /$ plant, respectively. The increasing dry weight during the growth period resulted in an increase in $J_{\mathrm{w}}$, which can be attributed to an increase in root surface area (Kramer and Boyer, 1995). There was no difference in $J_{\mathrm{w}}$ between the Org-N and Control treatments. Figure 4 shows the relationships between $[\mathrm{Gly}]_{\mathrm{Xy}},[\mathrm{Ala}]_{\mathrm{Xy}}$, and $[\mathrm{Met}]_{\mathrm{Xy}}$ and the root dry weight. For the Org-N treatment, these concentrations did not depend on the dry weight and showed almost constant values, which differed according to the type of organic $\mathrm{N}$ and were approximately one-eighth to one-third of the levels found in the chamber $\left(2 \mathrm{mmol} \mathrm{L}{ }^{-1}\right)$. The data for $J_{\mathrm{Gl}}, J_{\mathrm{Ala}}$, and $J_{\mathrm{Met}}$, which were evaluated from $J_{\mathrm{W}}$ and $[\mathrm{Gly}]_{\mathrm{Xy}}$, [Ala $]_{\mathrm{Xy}}$, [Met $]_{\mathrm{Xy}}$, at different root

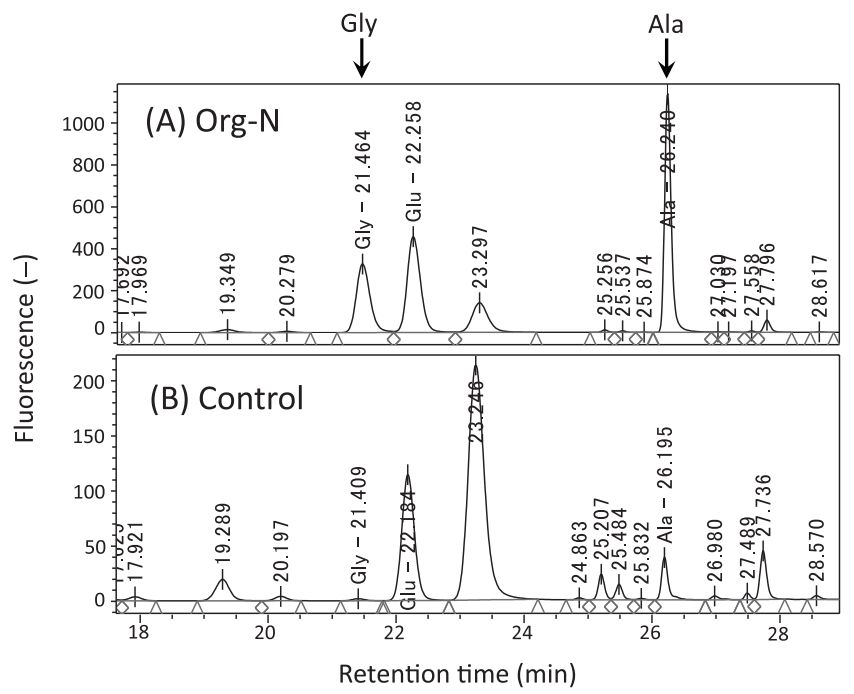

Fig. 2 Examples of chromatograms obtained by high-performance liquid chromatography performed on the xylem sap obtained from the roots in the nutrient solution applied with (A: Org-N treatment) or without organic nitrogen (B: Control treatment).

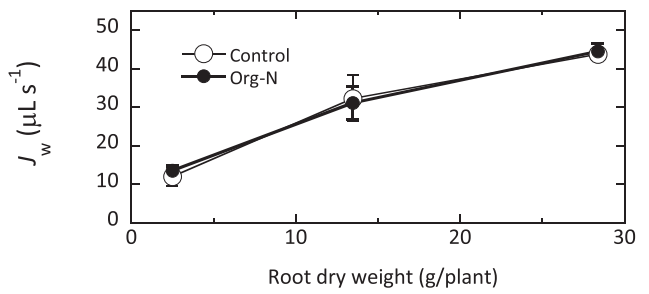

Fig. 3 Relationship between water uptake rate $\left(J_{\mathrm{w}}\right)$ and dry weight of the roots in the nutrient solution applied with $(\mathrm{Org}-\mathrm{N})$ or without organic nitrogen (Control). The means and standard error bars for 3 plants are shown. 


\section{DIRECT UPTAKE OF ORGANIC NITROGEN BY ROOTS}

dry weights are also shown in Fig. 4. The rates of uptake of organic $\mathrm{N}$ increased with dry weight; this was caused by the increased $J_{\mathrm{w}}$ due to root growth (Fig. 3).

The values of $J_{\text {Gly }}$ and $J_{\text {Ala }}$ were almost the same, but the $J_{\text {Met }}$ value was always significantly lower during the growing period. Spoerl (1948) indicated the possibility that plant's demand for amino acids as $\mathrm{N}$ source varies depending on the growth stage. However, such behavior was not observed in this study. On the other hand, the differences among the $J_{\text {Gly }}, J_{\text {Ala, }}$ and $J_{\text {Met }}$ values might be one of the reasons for the results obtained by Ghosh and Burris (1950), in which growth delay occurred in tomato plants when methionine was used as $\mathrm{N}$ source and not by glycine or alanine.

Gly, Ala, and Met were scarcely detected in the root xylem sap taken from the Control treatment, suggesting that their uptake was extremely low. This is further evidence for direct uptake of organic $\mathrm{N}$ by roots in the Org-N treatment. Thus, the results of Exp. I suggest that the tomato root has the ability to absorb organic $\mathrm{N}$ directly and plant growth increases the direct uptake through increased water uptake.

Figure 5 shows the relationship between $J_{\mathrm{w}}$ and pressure applied to the root chamber $(P)$ for the Org-N and Control treatments in Exp. II. Increasing $P$ induced an increase in $J_{\mathrm{w}}$ from approximately 3 to $20 \mu \mathrm{L} \mathrm{s}^{-1}$, which corresponds to the usual uptake range during the day. No difference in $J_{\mathrm{w}}$ was found when comparing the data from the 2 treatments. Figure 6 shows the relationships of [Gly $]_{\mathrm{xy}}$ and $J_{\mathrm{Gly}}$ with $J_{\mathrm{w}}$. In the Org-N treatment, [Gly] $]_{\mathrm{X} y}$ was not affected by $J_{\mathrm{w}}$ and was almost constant approximately $0.7 \mathrm{mmol} \mathrm{L}^{-1}$, and therefore $J_{\text {Gly }}$ increased with $J_{\mathrm{w}}$, whereas they were very low values in the Control treatment. Similar patterns were observed in [Ala $]_{\mathrm{xy}}$ and $J_{\text {Ala }}$ (data not shown), which agree with the data obtained in Exp. I (Fig. 4). On the other hand, different patterns were observed in the relationships of $\left[\mathrm{NO}_{3}^{-}\right]_{\mathrm{xy}}$ and $J_{\mathrm{NO}}$ with $J_{\mathrm{W}}$ (right panel in Fig. 6). [ $\left[\mathrm{NO}_{3}^{-}\right]_{\mathrm{xy}}$ for both treatments was fairly high at low $J_{\mathrm{W}}$ values and then decreased gradually with the increase in $J_{\mathrm{W}}$ eventually approaching the root zone concentration $\left(2 \mathrm{mmol} \mathrm{L}^{-1}\right.$ in the chamber). Active root
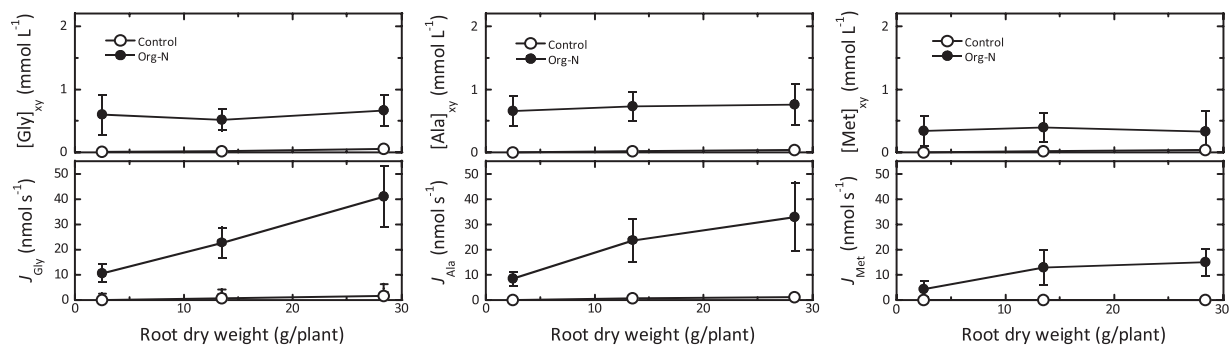

Fig. 4 Relationships of glycine, alanine, and methionine concentrations in the xylem sap ([Gly $]_{x y}$, [Ala $]_{x y}$, and $[\mathrm{Met}]_{\mathrm{Xy}}$, respectively) and glycine, alanine, and methionine uptake rates $\left(J_{\mathrm{Gly}}, J_{\mathrm{Ala}}\right.$, and $J_{\mathrm{Mct}}$, respectively) with the dry weight of the roots in the nutrient solution applied with $(\mathrm{Org}-\mathrm{N})$ or without organic nitrogen (Control). The means and standard error bars for 3 plants are shown.

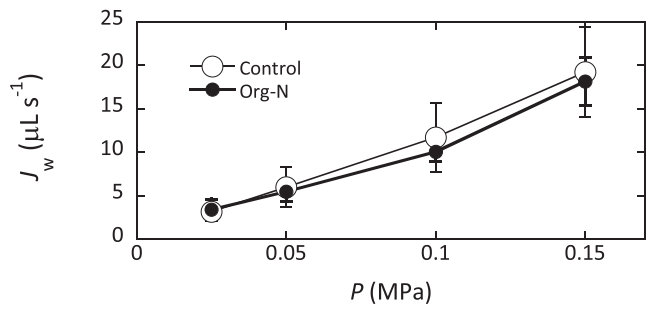

Fig. 5 Relationship between water uptake rate $\left(J_{\mathrm{w}}\right)$ and pressure applied to the roots in nutrient solution applied with (Org-N) or without organic nitrogen (Control). The means and standard error bars for 3 plants are shown. 


\section{YASUTAKE ET AL.}

uptake of $\mathrm{NO}_{3}^{-}$would induce higher values of $\left[\mathrm{NO}_{3}^{-}\right]_{x y}$ (Taiz and Zeiger, 2006). Such behavior between $\left[\mathrm{NO}_{3}^{-}\right]_{\mathrm{xy}}$ and $J_{\mathrm{w}}$ has been reported in previous studies (e.g. Schurr, 1998). As a result, $J_{\mathrm{NO}}$ either remained at the same level or increased slightly with increasing $J_{\mathrm{w}}$. There were no significant differences in $\left[\mathrm{NO}_{3}^{-}\right]_{\mathrm{Xy}}$ and $J_{\mathrm{No}}$, between the Org-N and Control treatments; this means that there is little interaction between organic and inorganic $\mathrm{N}$ uptake by roots. Figure 7 shows the relationship between the ratio of organic $\mathrm{N}$ uptake $\left(J_{\mathrm{Gly}}+J_{\mathrm{Ala}}\right)$ to the total $\mathrm{N}$ uptake $\left(J_{\mathrm{Gly}}+J_{\mathrm{Ala}}+\right.$ $J_{\mathrm{NO}}$ ) and $J_{\mathrm{w}}$ for the Org-N treatment. The ratio increased from approximately $15 \%$ to $40 \%$ with increasing $J_{\mathrm{w}}$. These values were moderately consistent with the report by Warren (2009). Thus, the results of Exp. II. suggest that higher daytime root water uptake induces a higher rate of organic $\mathrm{N}$ uptake and further a role of $\mathrm{N}$ sources as nutrient for plants changes dynamically during the day.

In this study, the direct uptake of organic nitrogen by the tomato roots was analyzed using the root chamber with HPFM developed by Yasutake et al. (2011), and its relations to plant growth and water uptake were evaluated quantitatively. The information obtained herein will help to further our understanding of plant nutrient acquisition/utilization and to optimization of fertilizer management.

This study was financially supported by Grants-in-Aid for Scientific Research (No.22780231 and 23380150) from the Japan Society for the Promotion of Science and a research fund from Natural Sciences Cluster Projects of Kochi University. The authors express their gratitude to Mr. Michio Hamakoga
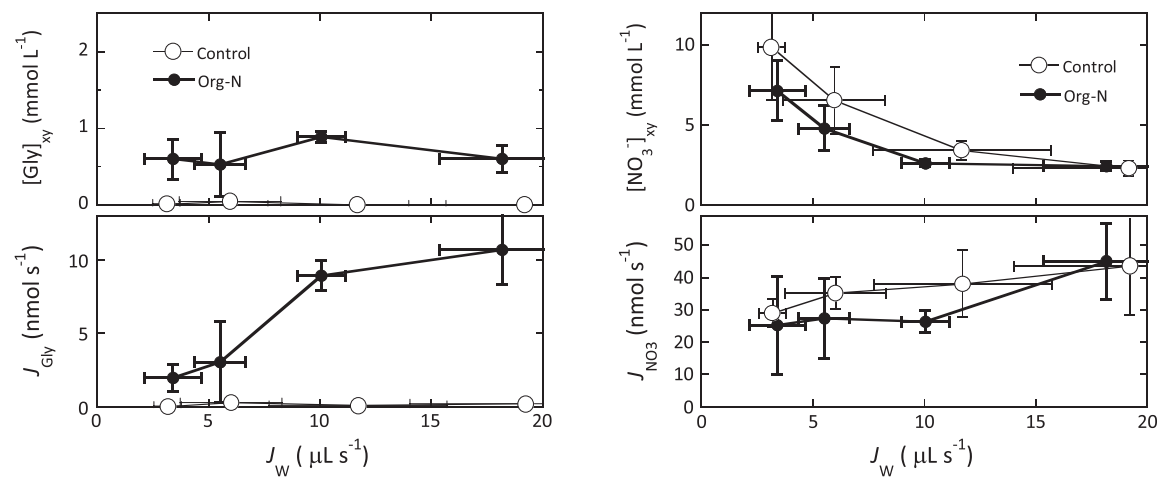

Fig. 6 Relationship of glycine and nitrate nitrogen concentrations in the xylem sap $\left([\mathrm{Gly}]_{\mathrm{xy}}\right.$, and $\left[\mathrm{NO}_{3}^{-}\right]_{\mathrm{xy}}$, respectively) and glycine and nitrate nitrogen uptake rates $\left(J_{\mathrm{Gly}}, J_{\mathrm{NO}}\right)$ with water uptake rate $\left(J_{\mathrm{W}}\right)$ of the roots in nutrient solution applied with $(\mathrm{Org}-\mathrm{N})$ or without organic nitrogen (Control). The means and standard error bars for 3 plants are shown.

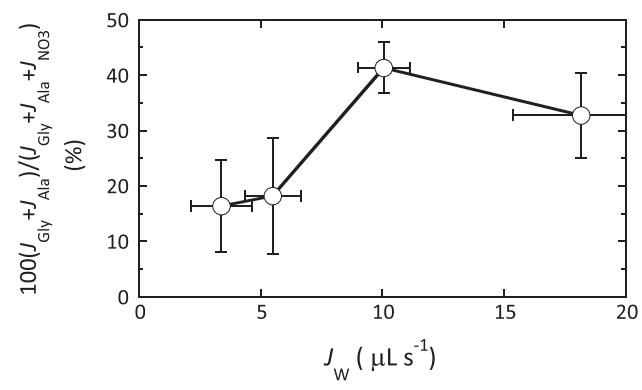

Fig. 7 Relationship between ratio of the summation of glycine and alanine uptake rates $\left(J_{\mathrm{Gly}}+J_{\mathrm{Ala}}\right)$ to the summation of glycine, alanine, and nitrate nitrogen uptake rates $\left(J_{\mathrm{Gly}}+J_{\mathrm{Ala}}+J_{\mathrm{No}}\right)$ and water uptake rate $\left(J_{\mathrm{w}}\right)$ of the root for the Org-N treatment. The means and standard error bars for 3 plants are shown. 


\section{DIRECT UPTAKE OF ORGANIC NITROGEN BY ROOTS}

(Kyushu University) for his technical assistance.

\section{REFERENCES}

Ge, T., Song, S., Roberts, P., Jones, D. L., Huang, D., Iwasaki, K. 2009. Amino acids as a nitrogen source for tomato seedlings: The use of dual-labeled $\left({ }^{13} \mathrm{C},{ }^{15} \mathrm{~N}\right)$ glycine to test for direct uptake by tomato seedlings. Environ. Exp. Bot. 66: 357-361.

Ghosh, B. P., Burris, R. H. 1950. Utilization of nitrogenous compounds by plans. Soil Sci. 70: 187-204.

Hirner, A., Ladwig, F., Stransky, H., Okumoto, S., Keinath, M., Harms, A., Frommer, W. B., Koch, W. 2006. Arabidopsis LHT1 is a high-affinity transporter for cellular amino acid uptake in both root epidermis and leaf mesophyll. Plant Cell 18: 1931-1946.

Jones, D. L., Healey, J. R., Willett, V. B., Farrar, J. F., Hodge, A. 2005. Dissolved organic nitrogen uptake by plants - an important N uptake pathway? Soil Biol. Biochem. 37: 413-423.

Kramer, P. J., Boyer, J. S. 1995. Water Relations of Plants and Soils. Academic Press, San Diego, pp 495.

Lee, Y. H., Foster, J., Chen, J., Voll, L. M., Weber, A. P. M., Tegeder, M. 2007. AAP1 transports uncharged amino acids into roots of Arabidopsis. Plant J. 50: 305-319.

Matsumoto, S., Noriharu, A., Yamagata, M. 2000. Possible direct uptake of organic nitrogen from soil by chingensai (Brassica campestris L.) and carrot (Daucus carota L.). Soil Biol. Biochem. 32: 1301-1310.

Nagasuga, K., Kubota, F. 2012. Changes in total hydraulic resistance and morphological traits in stem segment of napiergrass (Pennisetum purpureum Schumach.) under shade condition. Environ. Control Biol. 50: accepted.

Nagasuga, K., Yasutake, D., Araki, T., Kitano, M. 2000. Methodological establishment for individual evaluations of hydraulic conductances of node, internode and leaf insertion in a nodal complex. Biotronics 29: 71-78.

Näsholm, T., Huss-Danell, K., Högberg, P. 2001. Uptake of glycine by field grown wheat. New Phytol. 150: 59-63.

Nihei, N., Masuda, S., Noda, A., Tanoi, K., Rai, H., Nakanishi, M. T. 2009. A study of glutamine uptake by rice roots. (099-2), International Symposium "Root Research and Applications", September, Vienna, Austria.

Nihei, N., Masuda, S., Rai, H., Nakanishi, M. T. 2008. Imaging analysis of direct alanine uptake by rice seedlings. Radioisotopes 57: 361-366.

Sago, Y., Yasutake, D., Hidaka, K., Yasunaga, E., Eguchi, T., Yoshida, S., Kitano, M. 2011. Kinetics of root ion absorption affected by environmental factors and transpiration II. Environmental effects and a concentration-dependent model. Environ. Control Biol. 49: 33-40.

Schurr, U. 1998. Xylem sap sampling - new approaches to an old topic. Trends Plant Sci. 3: $293-298$.

Spoerl, E. 1948. Amino acids as sources of nitrogen for orchid embryos. Am. J. Bot. 35: 88-95.

Svennerstam, H., Ganeteg, U., Bellini, C., Näsholm, T. 2007. Comprehensive screening of Arabidopsis mutants suggests the Lysine Histidine Transporter 1 to be involved in plant uptake of amino acids. Plant Physiol. 143: 1853-1860.

Taiz, L., Zeiger, E. 2006. Plant Physiology, 4th edition. Sinauer Associates, Sunderland, pp 764.

Warren, C. R. 2009. Why does temperature affect relative uptake rates of nitrate, ammonium and glycine: A test with Eucalyptus pauciflora. Soil Biol. Biochem. 41: 778-784.

Yasutake, D., Kitano, M., Nagasuga, K., Araki, T., Osman, A. K., Ishikawa, K. 2011. Use of a high-pressure flowmeter for evaluating hydraulic characteristics of plant organs and absorption functions of roots. Environ. Control Biol. 49: 99-105. 